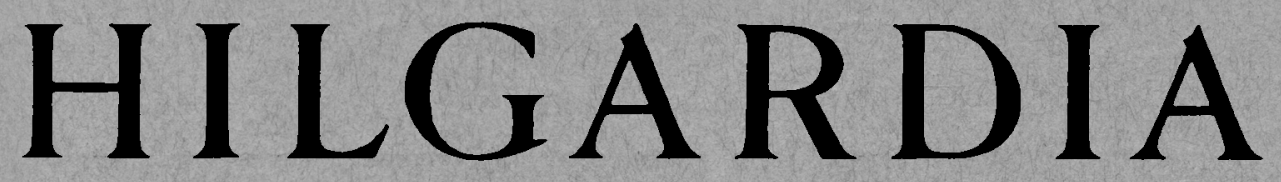

A Journal of Agricultural Science Published by the California Agricultural Experiment Station

\title{
THE NATURE AND DEVELOPMENT OF NONINFECTIOUS BUD FAILURE OF ALMONDS
}

E. E. WILSON and RICHARD D. SCHEIN 
The almond-tree disorder known as almond bud failure occurs to a moderate extent in the Nonpareil and Peerless varieties, but is widespread in the Jordanolo variety chiefly in the Sacramento Valley. Other varieties thought to be affected are the Texas and the Jubilec, although this has not yet been verified.

The primary symptom of the disorder is the failure of buds to grow. Secondary symptoms include excessive shoot production, delay in blossoming, and bark necrosis.

Tests of Nonpareil, Peerless, and Jordanolo buds and scions have failed to show that the disorder is infectious. Bud failure, however, developed in the growth from a high percentage of buds and scions from affected trees. It is concluded, therefore, that the disorder is bud-perpetuated.

Bud-failure symptoms develop in scions growing on different rootstocks, including peach, bitter almond seedlings, and the Texas almond scedling.

There is some evidence that vegetative propagation tends to increase the manifestation of symptoms in the Jordanolo variety. Severe pruning of affected trees also apparently tends to increase the severity of symptom expression.

Almond bud failure is transmitted through the seed. Fourteen per cent of one lot of seedlings produced from seeds of affected Nonpareil almond trees exhibited loss of buds and bark necrosis within 2 to 4 years after planting. 


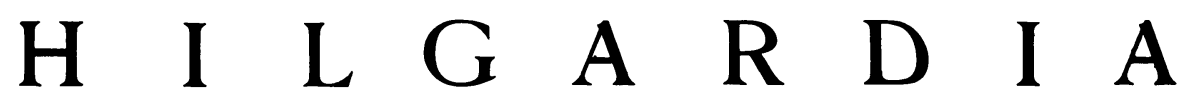

A Journal of Agricultural Science Published by

the California Agricultural Experiment Station

VOL. 24

APRIL, 1956

No. 18

\section{THE NATURE AND DEVELOPMENT OF NONINFECTIOUS BUD FAILURE OF ALMONDS ${ }^{1}$}

\section{E. E. WILSON ${ }^{2}$ and RICHARD D. SCHEIN ${ }^{3}$}

THIS ARTICLE is intended to supplement and expand existing accounts of a noninfectious almond tree disorder whose outstanding symptom, and the only one to develop consistently, is the failure of the buds to grow. Only one type of such a disorder was known when studies were begun in 1941. This occurred in the Nonpareil and Peerless varieties. A similar but distinct disorder was reported in the Drake variety a few years later. It was readily transmitted by budding or grafting and, consequently, the so-called "Drake almond bud failure" was listed as a virus disease in later accounts. It will be referred to here as the virus-type or Drake-type bud failure. The disorder of the Nonpareil and Peerless varieties, on the other hand, was not transmitted by budding or grafting, even after repeated attempts. It was, therefore, called "almond bud failure" in subsequent reports and listed as a "viruslike" disorder of unknown origin (Stout and Wilson, 1947; Wilson and Stout, 1944, 1951 a, and 1951b). It will be referred to here as bud failure.

In 1948 a bud-failure disorder similar to that in Nonpareil and Peerless was found in the Jordanolo variety (Wilson, 1950). This new almond was first distributed about 1934, grew more popular in succeeding years (Wood, 1939), and became one of the varieties most commonly planted after 1940 .

More recently bud-failure disorders have been found in the Jubilee, Texas (Mission), and Marcona varieties. Whether bud failure in these varieties is of the Nonpareil-Peerless type or of the Drake type is not yet proved. Though symptomatic differences between the two disorders are discernible, these differences are manifested only at certain times of the year and then only in trees that have been affected for several years. Their diagnostic value is therefore limited. Hence, while the disorders in Jubilee and Texas are thought to be the Nonpareil-Peerless (noninfectious) type, identification is tentative until inoculation tests are completed. Such tests require several years.

\footnotetext{
${ }^{1}$ Received for publication June 27, 1955.

${ }^{2}$ Professor of Plant Pathology and Plant Pathologist in the Experiment Station, University of California, Davis.

${ }^{3}$ Formerly Research Assistant in Plant Pathology, University of California, Davis. The phases contributed by the junior author were originally part of a thesis presented to the Graduate Division, University of California, at Davis, in partial fulfillment of the requirements for the degree of Doctor af Philosophy.
} 


\section{DISTRIBUTION}

Though almond bud failure is somewhat more prevalent in the Sacramento Valley than elsewhere, it occurs in many other almond-producing districts of the state. So far as can be determined from the literature, however, it has not been reported in other parts of the world.
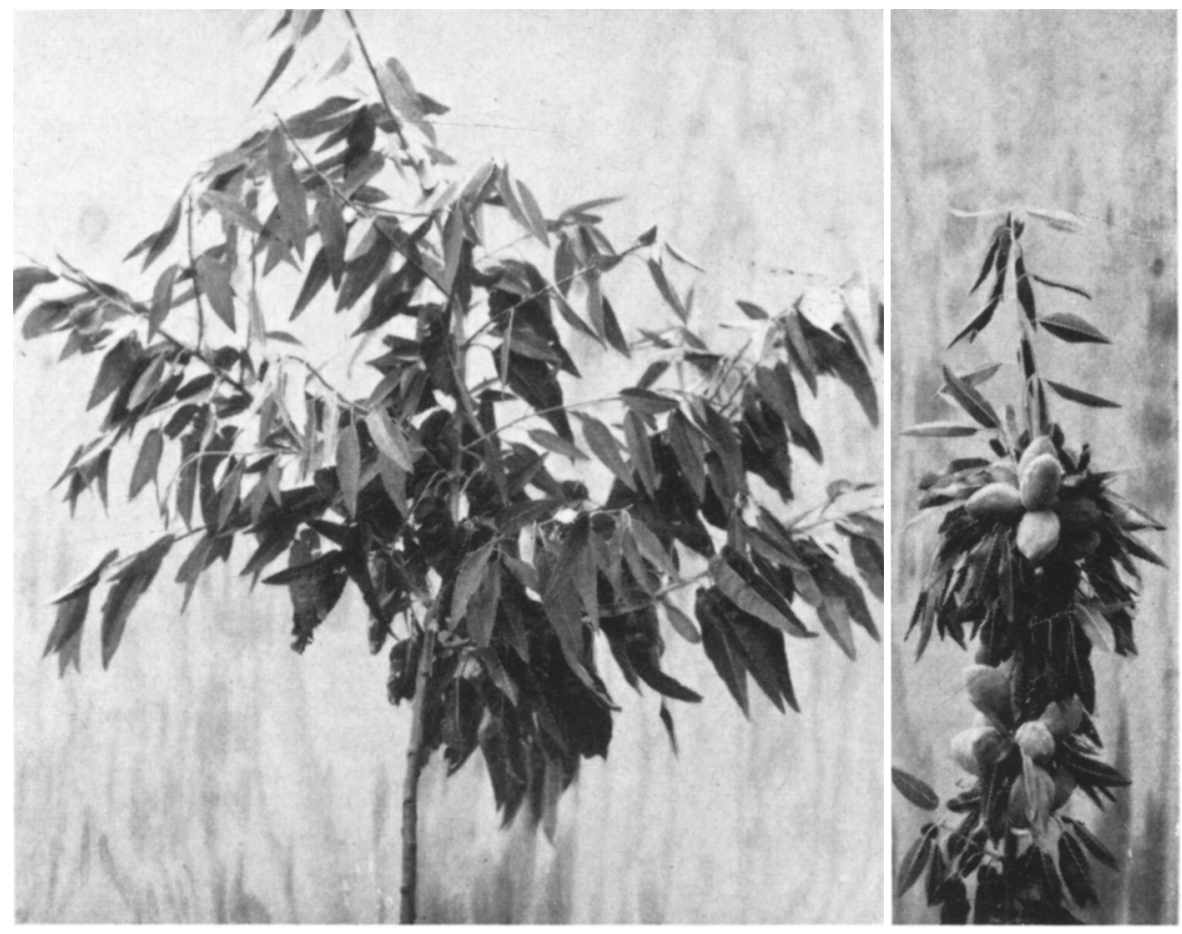

Fig. 1. (Left) Branch of a Jordanolo almond tree affected by noninfectious bud failure. All lateral buds failed except a few located near the end of the shoot. From these developed long shoots which produced branches the same growing season. (Right) Branch of a tree unaffected by bud failure. Most lateral leaf buds on such branches produce spurs which bear fruit and leaves the following year. Only the terminal bud and one or two lateral buds produce shoots.

\section{IMPORTANCE}

Almond bud failure is relatively widespread and serious in plantings of the Jordanolo variety. Orchards with 30 to 40 per cent of the Jordanolo trees affected are not uncommon. With the Nonpareil and Peerless varieties, on the other hand, it is only in occasional orchards that large numbers of trees are affected and crop losses are extensive.

\section{SYMPTOMS}

$\Lambda$ tree affected by bud failure is sparse in foliage with many of the twigs lacking leaves and others producting leaves at only a few nodes. Trees affected for several years will in that time produce an unusually large number 
of branches, some of which are clustered together at the base or tip of the supporting branch. Not infrequently the branches will have changed their direction of growth several times, some bending back upon themselves. This feature, illustrated in earlier publications (Wilson and Stout, 1944 and $1951 b)$, together with the presence of numerous shoots, gives the branch system a crooked, tangled appearance.

Such abnormalities are the consequence of repeated failures of many of the leaf buds ${ }^{4}$ to grow in the spring, and of a preponderant development of shoots from the buds that do grow (fig. 1). On shoots of nonaffected trees, a considerable proportion of the lateral buds produce spurs. With affected trees, however, relatively few of the viable lateral buds produce spurs; instead, shoots several inches long develop from most of the buds that grow. Moreover, soon after forming in summer, many axillary buds on affected twigs give rise to other shoots. Such secondary branching, though common in nonaffected trees while young, is relatively infrequent in nonaffected trees of bearing age.

A symptom of bud failure present in some varieties, though not in others, is a necrosis of the twig cortex (fig. 2). Necrotic spots, 4 to $10 \mathrm{~mm}$ in width, develop in fall or winter on the bark of twigs produced the preceding summer, ordinarily on a certain portion. On trees of the Jordanolo variety these spots were found to occur at corresponding positions on different twigs of the same or different trees. In the growing season, almond twigs normally undergo two or more stages of rapid elongation, alternating with stages of relatively slow elongation. In 1952, the necrotic spots occurred only on the portion of twig produced during the early stages of the second "flush" of growth of Jordanolo trees. In 1954 we observed a similar tendency on trees of that variety.

Since the necrosis neither involves the bark to a great depth nor all of the bark of the affected portion, twigs are not girdled and killed by the necrosis, though they may die if no leaves are produced on them. Phellogen activity in the cortex beneath the necrotic areas causes the outer bark to crack and become roughened (fig. 2, right). Consequently, the positions of the necrotic zones are marked for several years thereafter by bands of roughened bark. Examination of trees with such old rough-bark areas reveals that cortical necrosis seldom develops every year. Instead, 1 and sometimes 2 years elapse between manifestations of this symptom. In certain trees under observation, cortical necrosis developed each alternate year over a period of 8 years.

Cortical necrosis is common in affected trees of the Peerless and Jordanolo varieties. Although it is seldom if ever encountered in trees of the Nonpareil variety, it develops in seedlings of this variety. The Jordanolo variety, which arose as a seedling of Nonpareil, exhibits the condition even more frequently than the Peerless.

Incidence of cortical necrosis is correlated with the severity of bud-failure symptoms. In a young Jordanolo orchard, for example, rough-bark zones were found on only 17 per cent of trees with mild bud-failure symptoms,

4 In the almond, as in other stone-fruit species, leaves and flowers are produced in separate buds, which we shall designate leaf buds and flower buds, respectively. 


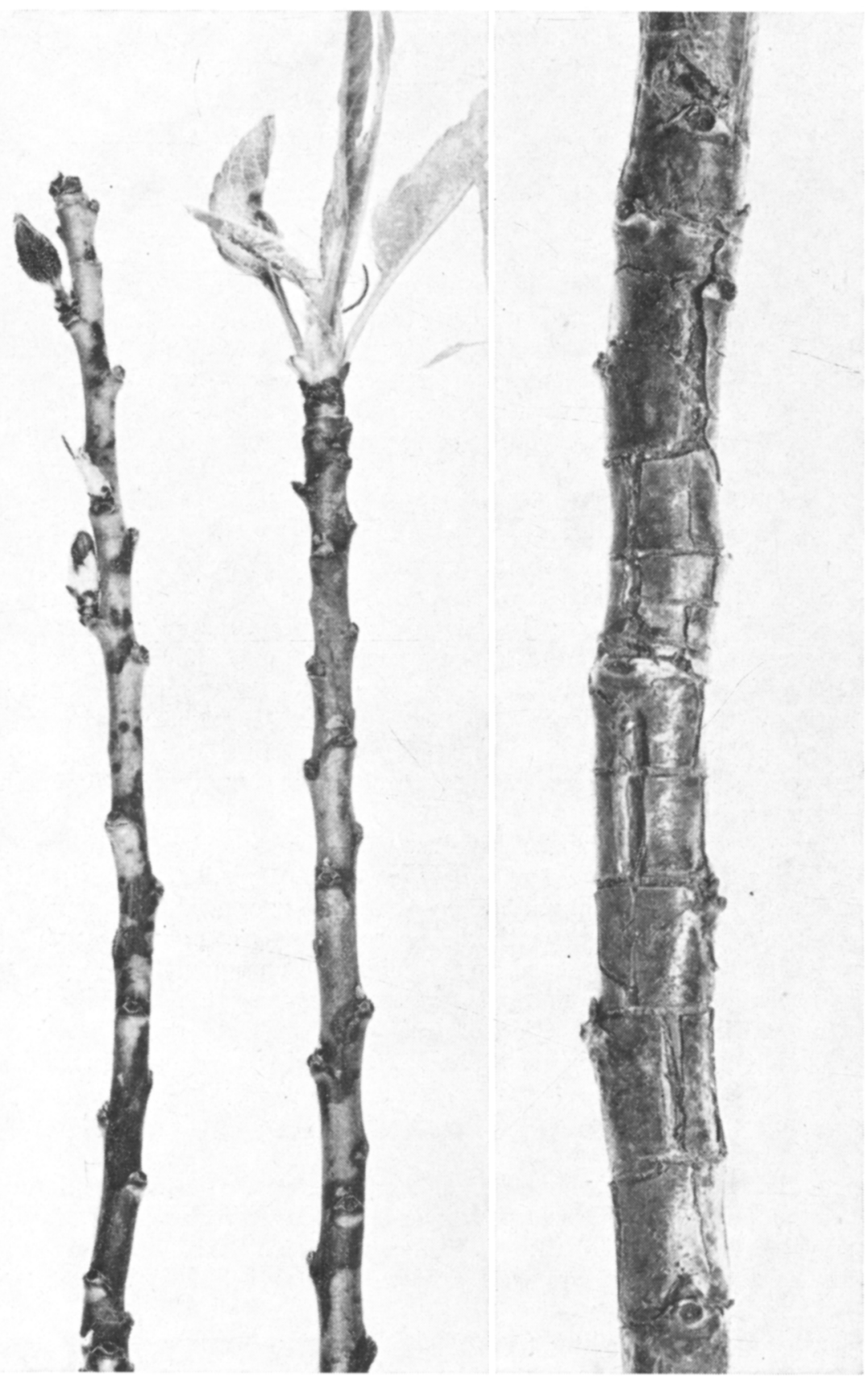

Fig. 2. (Left) The discolored blotehes (cortical necrosis) on the twigs are a symptom of noninfectious almond bud failure. Their distribution on twigs is variable. Few buds grow on such twigs. (Right) Cracking of outer bark on a twig which developed cortical necrosis the previous year. The rough bark usually persists for several years. 
on 60 per cent of trees with moderate symptoms, and on 100 per cent of the trees with severe symptoms.

Few leaf buds will remain viable on the portion of the twig with cortical necrosis, though an occasional flower bud may open, and sometimes set fruit.

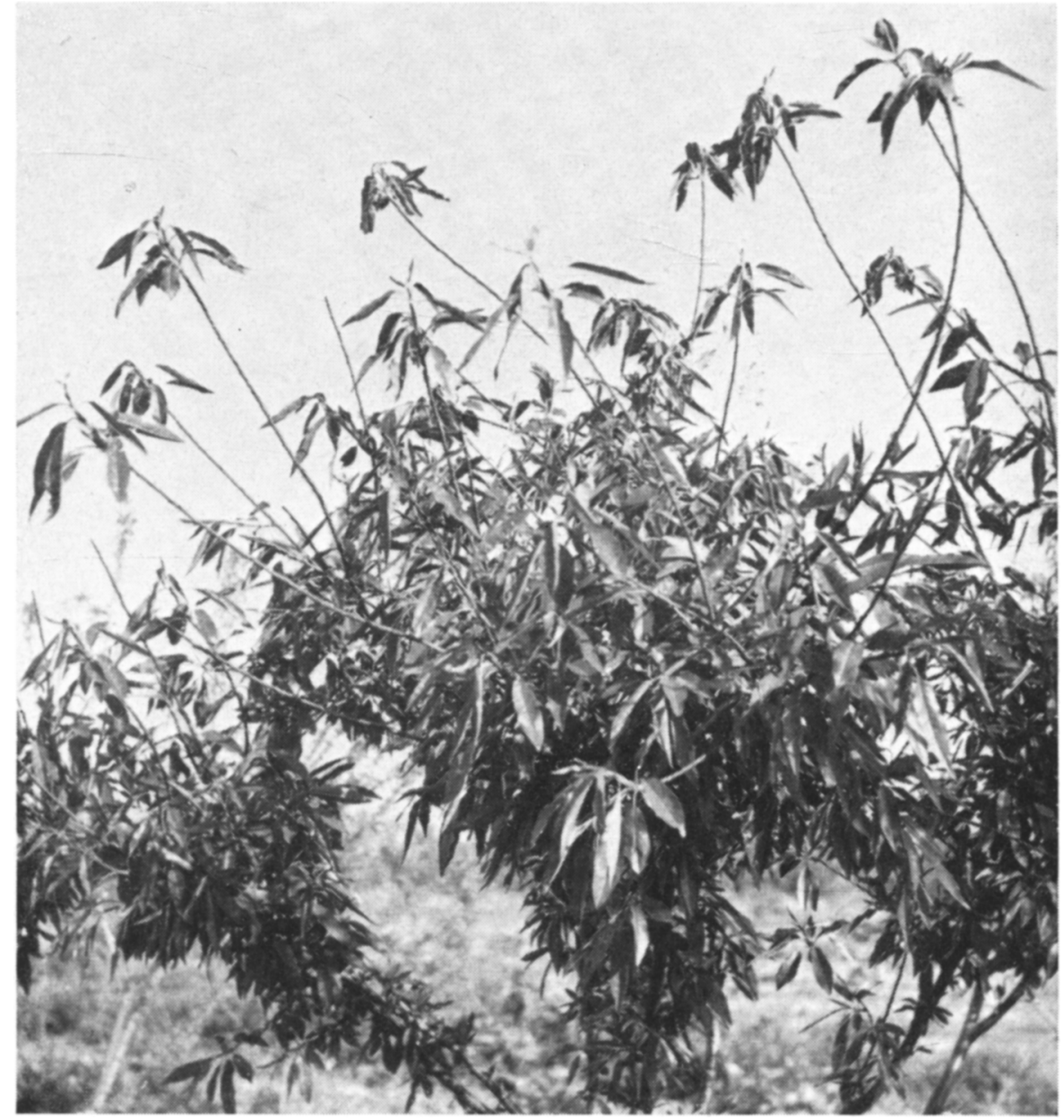

Fig. 3. Abnormal shoot growth on a young Jordanolo almond tree affected by the budfailure disorder. On some shoots only the terminal bud grew, on others no buds grew.

Except for this almost complete lack of bud growth in the rough-bark areas, bud failure follows no consistent pattern. On young trees, entire shoots may be devoid of viable lateral beds. The young tree shown in figure 3 developed no viable lateral buds on about 70 per cent of the new shoots during 2 years, though 88 per cent of the terminal buds were viable and, upon growing, produced the long, whiplike shoots shown in the picture. Such behavior is not uncommon in affected young trees, but becomes progressively less ap- 


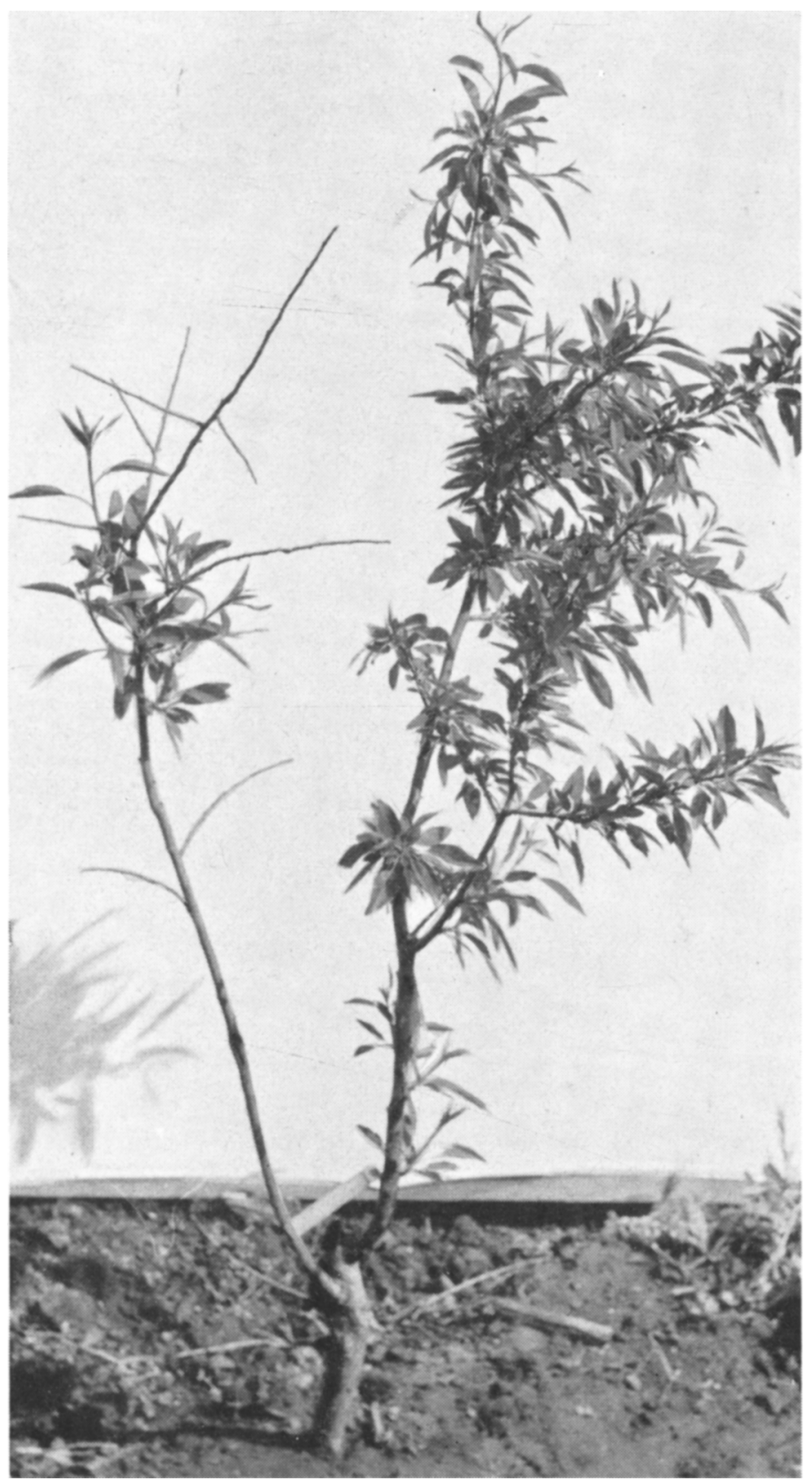

Fig. 4. Contrasting development on the same stock of branches from an affected bud (left) and a nonaffected bud (right) illustrates the bud perpetuation of almond bud failure. 
parent as they begin to bear. At this time, bud failure may occur on any portion of the shoots, terminal bud failure being no less frequent than failure of the lateral buds.

On the whole, the twigs of affected trees are somewhat more slender than those of nonaffected ones, though this feature is by no means consistent. Shoot length is not reduced; in fact, affected trees may reach greater heights than unaffected trees, because of branch elongation through continued shoot development after the tree reaches bearing age.

No abnormality is discernible in the shape or color of leaves and flowers on affected trees. Flower-bud opening, however, sometimes is later in affected than in nonaffected trees.

\section{TRANSMISSION TESTS}

In the Nonpareil and Peerless Varieties. Though tests of transmission of bud failure have been made for Nonpareil and Peerless varieties, and results reported (Stout and Wilson, 1947), the extent and nature of the tests have not been described. The first tests, in 1941, consisted of inoculating young, nonaffected Drake and Peerless almond trees with material from severely affected Peerless trees. A second and more extensive series of tests, begun in 1942, consisted of inoculating young, nonaffected Nonpareil trees with material from three lots of affected Nonpareil trees and two lots of affected Peerless. The inoculum consisted of scions collected in January and stored at low temperature until they were placed on the trees in March. Other scions were taken from the same affected orchards in March, and again in June, July, and August. These were transferred to nonaffected trees within a few days of collecting them. Inoculation was performed in three ways: by shield budding, whip grafting, and heel grafting. Heel grafting is similar to shield budding except that the scion consists of a small bark shield bearing a lateral twig instead of a single bud. This twig is cut from the supporting branch and is inserted into a bark slit in the same manner as a shield bud. Since trees with bud failure produce buds that are low in vitality, heel grafting was thought to be more reliable than shield budding for obtaining growth from the scions. Although it was learned later that growth of the scion is not necessary for transmission of the virus type of bud failure, growth from the scions was desired in these tests for studying the scion-perpetuation feature of bud failure (fig. 4).

The total number of trees inoculated in these two tests was 167 . Well over 100 scions grew. Table 1 summarizes the status of bud failure in the scions 4 years after they were placed in the understock. By this time 90 per cent of the Nonpareil scions and 83 per cent of the Peerless scions exhibited symptoms of bud failure. Scions from the Peerless variety were somewhat slower in developing symptoms than were those from the Nonpareil variety. Ten per cent of the Nonpareil scions and 17 per cent of the Peerless scions were without symptoms at this time, and certain ones remained symptomless until the end of the test, in 1952.

Although in some affected scions bud failure became progressively more pronounced with the passage of time, others continued to exhibit very mild symptoms until the end of the experiment. This feature has been noted in 
orchard trees and will be discussed more fully in the section, "Variability in Symptom Development."

Judging from the data in table 2, scions collected during the dormant season carry bud failure almost as frequently as those collected during the growing season. Propagation of trees from affected sources is apparently hazardous at any time of the year.

TABLE 1

PER CENT OF SCIONS DEVELOPING BUD-FAILURE SYMP. TOMS FOUR YEARS AFTER TRANSFER FROM SEVERELY AFFECTED ALMOND TREES TO NONAFFECTED UNDERSTOCK

\begin{tabular}{|c|c|c|}
\hline \multirow{2}{*}{ Symptom class } & \multicolumn{2}{|c|}{$\begin{array}{c}\text { Per cent of scions } \\
\text { developing symptoms }\end{array}$} \\
\hline & Nonpareil & Peerless \\
\hline None. . & 10 & 17 \\
\hline Mild...... & 67 & 66 \\
\hline Moderate.............. & 13 & 12 \\
\hline Severe $\ldots \ldots \ldots \ldots \ldots \ldots \ldots \ldots \ldots$ & 10 & 5 \\
\hline
\end{tabular}

TABLE 2

DEVELOPMENT OF BUD-FAILURE SYMPTOMS BY SCIONS REMOVED FROM AFFECTED TREES IN WINTER AND SUMMER AND GROWN FOUR YEARS ON NONAFFECTED TREES

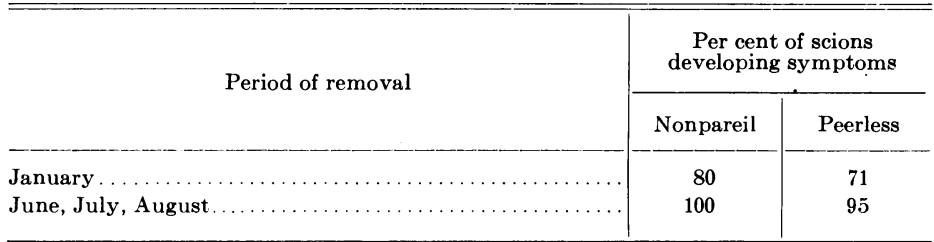

Although all the 167 trees with growing affected scions were kept under observation for 6 years, and some for 10 years, only one tree developed symptoms of bud failure. This was a tree of the Drake variety in which scions from an affected Peerless tree were growing. Since none of the other four Drake trees in this inoculation series developed symptoms, it is believed that this tree was naturally infected by the virus-type bud failure.

In a series of tests begun in 1941, root pieces from affected Nonpareil trees were grafted onto roots of young nursery trees of the same variety. These trees were grown for one season, dug during the winter, and replanted in another location the following spring. In four out of ten trees the root pieces had made a union with the root of the tree. These trees were grown for 4 years, during which time none developed symptoms of bud failure. 
In 1942 our attention was called to an orchard in which bud failure was very prevalent in the Nonpareil variety, and in which the grower had topworked a number of the affected trees, using Nonpareil scions obtained from a neighboring orchard in which no bud failure occurred. About 100 of these grafts were marked for identification and have been examined each year since. At present, 15 years after the trees were grafted, none of the branches produced from the scions has developed the disorder, while branches allowed to grow from below the graft union exhibit the symptoms. There was, therefore, no transmission from stock to scion.

In the Jordanolo Variety. Three series of transmission tests have been conducted with the disorder of the Jordanolo variety. The first, begun in 1948, consisted of inoculating young trees of the varieties Nonpareil, Peerless, Jordanolo, and Drake with buds from affected Jordanolo trees. Most of these bud shields united with the understock, but few of the buds grew. None of these trees have yet developed symptoms of the disorder, although trees inoculated the same year with buds from Drake and Nonpareil trees affected by the virus-type of bud failure developed symptoms 2 years later.

The second series of inoculation tests was made in 1951 and consisted of placing affected Jordanolo buds on young Drake and Nonpareil trees. This test continued for 3 years before it was abandoned. During this time no evidence of transmission was obtained.

The third series, begun in 1951 on young Drake, Peerless, and Nonpareil trees, is still in progress (1955). Two of the five inoculated Peerless trees developed symptoms of rough bark and bud failure the year after inoculation, whereas none of the inoculated Drake or Nonpareil have yet done so. The presence of the rough-bark symptom, which has not been found in Peerless trees affected by the virus-type bud failure, leaves little doubt that before the inoculation these two trees were already affected by the Nonpareil-Peerless type of disorder. Morever, appearance of symptoms so soon after inoculation has not been observed with the virus-type bud failure. This was apparently a case of inadvertent use of already affected trees for inoculation tests.

In one orchard, in 1951, Jordanolo trees affected with bud failure were top-worked with scions from supposedly nonaffected Jordanolo trees. Examination of these trees in 1955 showed that an occasional branch produced from these scions exhibited symptoms, but such symptoms seldom occurred on more than one scion in a tree. This is too low an incidence to indicate transmission from understock to scion. Subsequent discovery of the disorder in certain trees of the lot of Jordanolo trees from which the scions had been obtained makes it quite clear that some affected scions had been used in top-working these trees.

In another orchard, in 1950, affected Jordanolo trees were top-worked with scions from nonaffected Ne Plus Ultra trees. These scions have pro. duced branches with no symptoms of bud failure. Though the susceptibility of the Ne Plus Ultra variety to the virus-type of bud failure has not been demonstrated, all other varieties (Nonpareil, Peerless, Jordanolo) so far inoculated with this type have contracted it.

It is reported elsewhere (Wilson and Wagnon, 1955) that the virus type of bud failure apparently can be transmitted from almond to peach by 
budding. In parallel tests, however, peach trees which were inoculated with buds from Jordanolo trees that were affected by almond bud failure, developed no symptoms of such a disorder. Hence we have additional evidence that two types of bud failure exist, and that the disorder in Jordanolo is not the virus type.

Transmission through the Seed. Results of an experiment demonstrating the transmission of the disorder through the seeds were reported in an earlier brief report (Wilson, 1954). Seven per cent of the seedling trees produced by seeds from affected Nonpareil and Peerless trees show marked symptoms of both bud failure and bark necrosis. Moreover, certain seedlings that have so far displayed no definite symptoms were shown to carry the disorder. In one lot the number of trees with bud failure had increased to 14 per cent by 1955 .

In a second experiment, seed transmission of both bud failure and roughbark symptoms was demonstrated for the Jordanolo variety. Certain 3-yearold seedlings of this variety showed marked symptoms in 1955, others showed mild but unmistakable symptoms.

It is entirely probable, therefore, that the Jordanolo variety acquired the disorder through the seed. The Jordanolo is a seedling developed from a cross between Nonpareil (female parent) and Harriott. In the almondbreeding program at Davis, the Nonpareil has been used as the female parent in other crosses and several of the trees developing from these crosses have shown bud-failure symptoms. Moreover, two trees developing from a cross between the Ne Plus Ultra (female parent) and the Jordanolo have shown bud-failure symptoms resembling those of the Jordanolo. No such disorder has been observed in the Ne Plus Ultra variety. This occurrence, therefore, may possibly indicate that almond bud failure can be acquired via pollen from the male parent.

None of the 100 seedlings which developed from seeds taken from trees affected by the virus type of bud failure showed symptoms of that disease. Hence the virus-type bud failure is probably not transmitted through seed.

\section{EFFECT ON FLOWER AND LEAF BUDS}

Though the productivity of the tree is materially reduced by the budfailure disorder, many shoots almost devoid of foliage produce blossoms, with comparatively high proportions of the blossoms setting fruit. On the other hand, the productivity of the tree gradually diminishes because of a corresponding diminution in the number of blossoms produced. A partial explanation of such a situation was suggested when it was found that the buds at the first four or five subterminal nodes of affected shoots fail to grow as often as those at corresponding nodes on nonaffected twigs. On normal Nonpareil almond trees the buds at such nodes are most likely to be flower buds, borne singly (Brooks, 1940). At nodes below this level, some single flower buds and some single leaf buds develop. The most common occurrence, however, is a group of buds at each node. Such a group typically consists of a leaf bud flanked by two flower buds. At times only one flower bud develops, at others up to six buds develop, several of which may be leaf buds. 
A study was begun in 1951 to determine more precisely the effect of the disorder on both flower and leaf buds. With older trees, the vegetative growth of a nonaffected tree is distinctly less than that of an affected one.

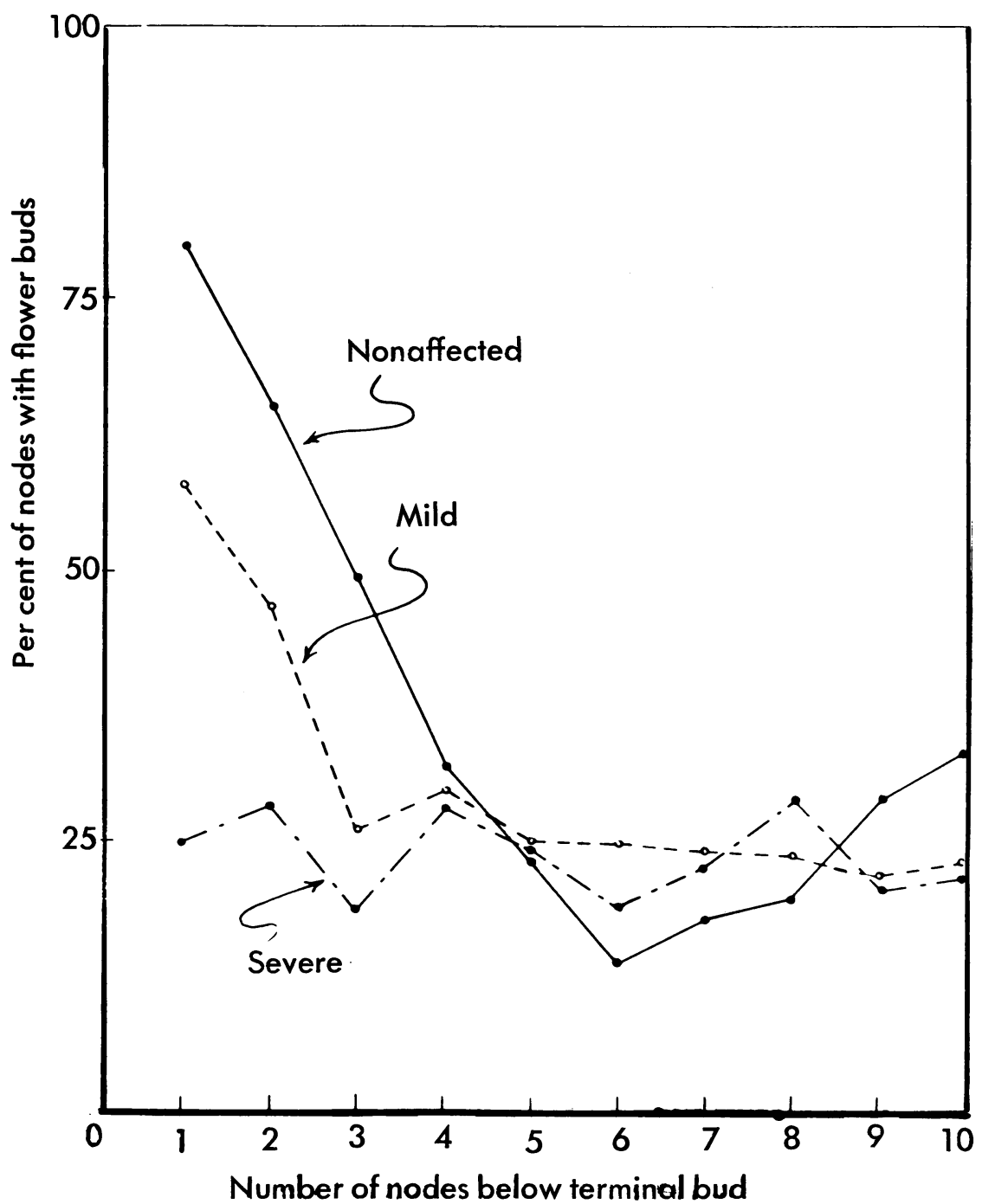

Fig. 5. Per cent of flower-bud production between the first and tenth nodes of 50 shoots on three Jordanolo almond trees displaying varying degrees of bud failure.

To obtain comparable shoot growth on which to make observations it was necessary, therefore, to select a young orchard. The orchard was located near Durham. Three 5-year-old trees of the Jordanolo were chosen: one had no visible symptoms of the disorder, one had mild symptoms, and one had severe symptoms. On December 8, 50 marked shoots of uniform length on 
each tree were examined and the type of bud or buds produced on the first 10 nodes below the terminal of each was recorded. At that time of the year flower buds can be distinguished from leaf buds by differences in size and

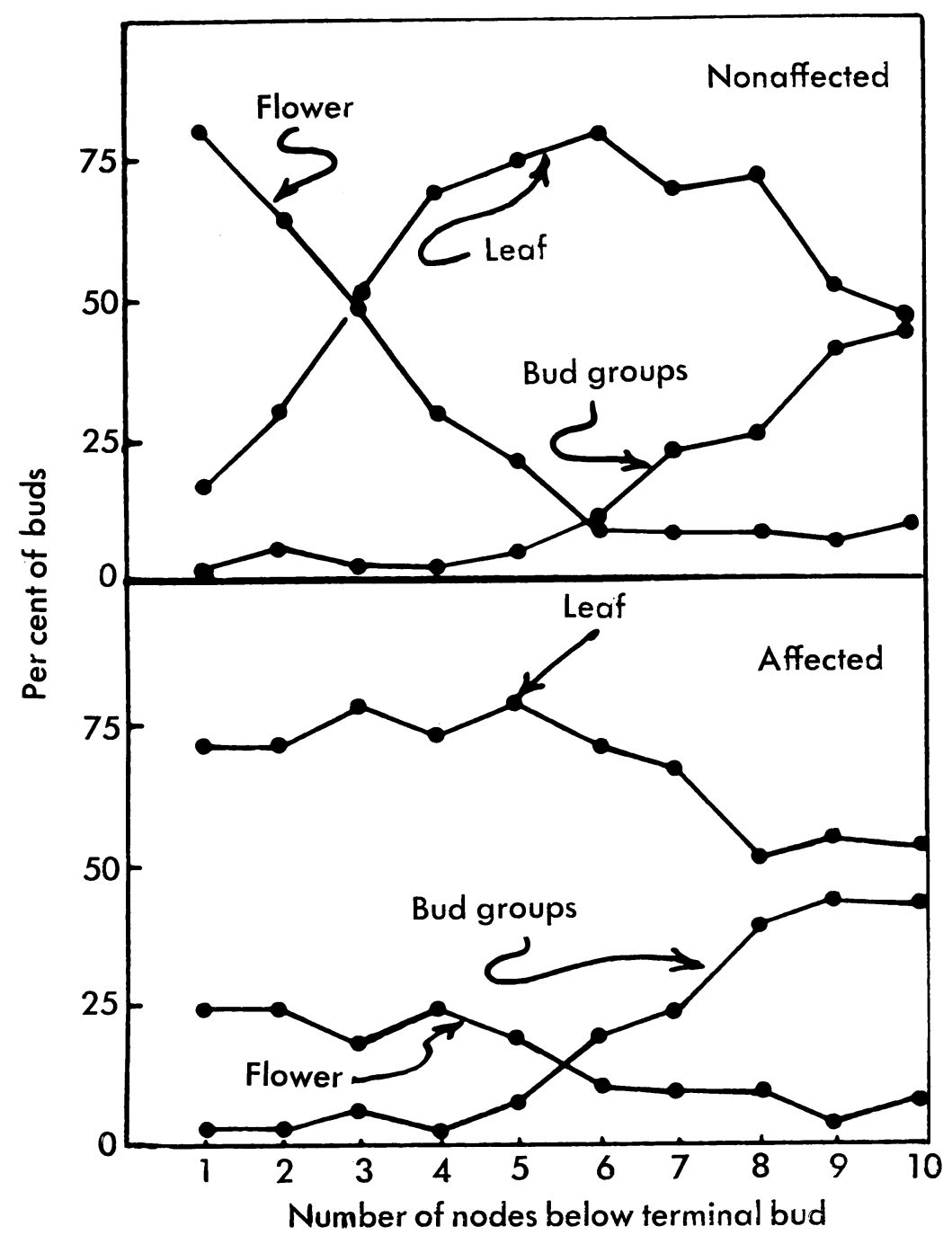

Fig. 6. Per cent of nodes producing single flower buds, single leaf buds, and bud groups on Jordanolo almond trees displaying varying degrees of bud failure.

shape. On February 29, 1952, after growth had begun, the buds were again examined. The growth or failure of growth of each was recorded. The results appear in figures 5 to 8 . In figure 5 the data are analyzed according to the type of bud or buds produced. For shoots of the nonaffected tree, 80 , 65 , and 50 per cent of the buds produced, respectively, at the first, second, and third subterminal nodes, contained flowers. The corresponding per- 
centages were 56,46 , and 25 for the mildly affected tree and 24,27 , and 19 for the severely affected tree. From the fourth to the tenth nodes there were no consistent differences in flower-bud production among the three trees.

For figure 6 the nodes of these trees were divided into three categories: (1) those producing single flower buds, (2) those producing single leaf buds, and (3) those producing bud groups. Production of single flower

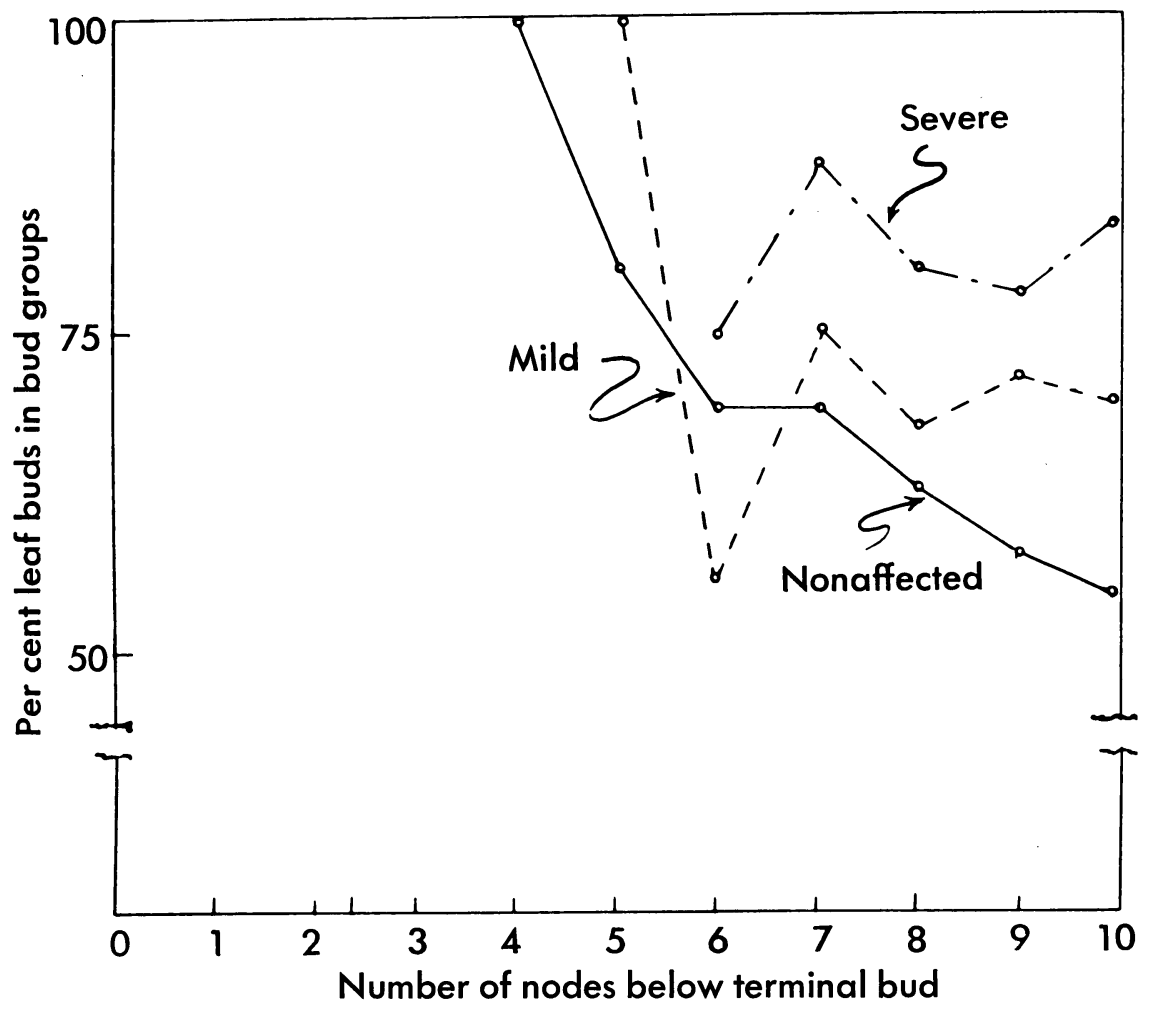

Fig. 7. Per cent of leaf-bud production from bud groups on Jordanolo almond trees displaying varying degrees of bud failure.

buds at the first four or five subterminal nodes was lower and production of leaf buds correspondingly higher for the two affected trees than for the nonaffected one. Below the fifth node, however, the frequency of the two types of buds did not differ between affected and nonaffected trees. No effect of the disorder on the bud groups was apparent.

Figure 7 reports the frequency with which leaf buds were produced in the bud groups. On the whole, the data suggest that leaf buds were more frequent in the bud groups of affected than in those of nonaffected trees.

Figure 8 compares the frequency of bud failure in the severely affected and the nonaffected tree. Failure of both types of buds on the nonaffected tree was less than 9 per cent, but the failure of both types of buds on the affected tree ranged between 37 and 81 per cent at different nodes. Failure 


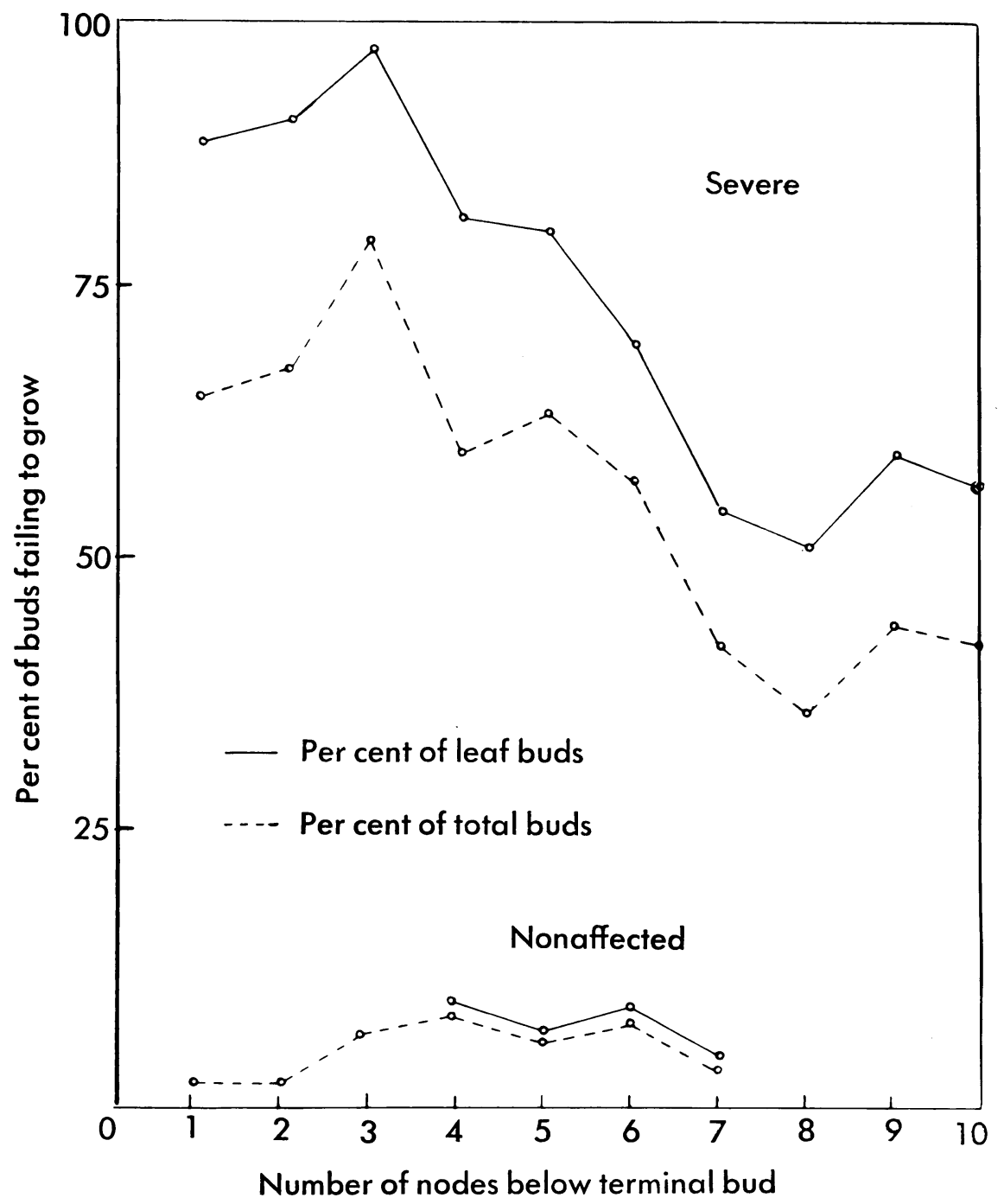

Fig. 8. Per cent of buds failing on a tree of the Jordanolo almond variety severely affected with noninfectious bud failure and on a nonaffected tree.

of the leaf buds alone was even higher, being 52 to 98 per cent, depending on distance from the terminal bud.

To procure additional information on the effect of the disorder on flowerbud and leaf-bud production and survival, the orchard near Durham was examined again in 1953. In late February, after growth had started, records on bud production were collected on trees of both the Jordanolo and the Peerless varieties.

To determine the effect of the disorder on flower-bud and leaf-bud production, twenty-five shoots on each of four nonaffected trees and a like num- 
ber of shoots on each of two categories of trees (moderately affected and severely effected) were examined. The type and condition of the buds were recorded. In the Jordanolo variety, normal trees produced leaf buds at 19 per cent of the first five subterminal nodes. The corresponding value was 65 per cent for moderately affected trees and 68 per cent for severely affected trees. In the Peerless variety, normal trees produced leaf buds at 46 per cent of the first five subterminal nodes, while the most severely affected trees produced leaf buds at 73 per cent of these nodes. Furthermore, on severely affected trees of the Jordanolo variety, it was found that accessory (flanking) buds of the bud groups were often leaf buds. From some

\section{TABLE 3}

PER CENT OF BUDS FAILING AT THE MIDDLE NODES OF SHOOTS ON AFFECTED AND NONAFFECTED ALMOND TREES

\begin{tabular}{|c|c|c|c|}
\hline \multirow{2}{*}{ Variety and condition of tree } & \multirow{2}{*}{$\begin{array}{l}\text { Per cent of } \\
\text { nodes pro- } \\
\text { ducing two } \\
\text { accessory } \\
\text { buds* }\end{array}$} & \multicolumn{2}{|c|}{$\begin{array}{l}\text { Per cent of buds failing } \\
\text { to grow }\end{array}$} \\
\hline & & Flower buds & Leaf buds \\
\hline \multicolumn{4}{|l|}{ Peerless: } \\
\hline Nonaffected.. & 27 & 3 & 2 \\
\hline Affected...... & 31 & 10 & 25 \\
\hline \multicolumn{4}{|l|}{ Jordanolo: } \\
\hline Nonaffected. & 77 & 2 & 1 \\
\hline Affected $\ldots \ldots \ldots \ldots \ldots \ldots \ldots \ldots \ldots \ldots \ldots \ldots \ldots \ldots \ldots$ & 23 & 64 & 71 \\
\hline
\end{tabular}

* Accessory buds, situated on either side of a leaf bud, were mainly flower buds.

of these projected the tips of one or two minute leaves. Such buds seldom developed beyond this stage and most of them gradually declined and died.

The relative frequency of leaf-bud and flower-bud failure at the middle nodes of shoots 12 to 18 inches long was determined on 12 affected and 12 nonaffected trees of each of the two varieties. Bud groups were produced frequently at these nodes. However, the nonaffected trees of the two varieties differed greatly as to the composition of the bud groups (table 3). With Peerless, only 27 per cent of the nodes on normal shoots produced two accessory flower buds, while with Jordanolo 77 per cent did so. With Peerless, the disorder had no apparent effect on the composition of the bud group, while with Jordanolo the disorder reduced the number of accessory buds materially. The reduction evidently was due to a decrease in bud initiation and not to a failure of existing buds or bud initials.

The data in table 3 pertain to the failure of the existing buds of the bud groups. They show that the disorder caused both types of buds to fail. With Peerless, failure of leaf buds was the more frequent but with Jordanolo there was little difference in this respect.

The foregoing studies suggest that the disorder influences the bud system of the tree in three ways: (1) It reduces the number of flower buds initiated. Whether or not it reduces the initiation of leaf buds is questionable because even though some nodes are without visible leaf buds a bud primordium can usually be found by microscopic examination. (2) The 
disorder alters the ratio of flower buds to leaf buds. Evidence of this was seen in the abnormally high production of leaf buds both at the first three or four subterminal nodes and at the middle nodes where the accessory buds of bud groups are normally flower buds. (3) The disorder causes existing flower and leaf buds to fail. Leaf buds appear to fail somewhat more often than flower buds.

\section{VARIABILITY IN SYMPTOM DEVELOPMENT}

A striking feature of the disorder is the wide variation in symptoms among trees of identical age and origin. Among young trees propagated from a

TABLe 4

DISTRIBUTION OF BUD-FAILURE SYMPTOMS AMONG BRANCHES OF AFFECTED JORDANOLO TREES

\begin{tabular}{|c|c|c|c|}
\hline \multirow{2}{*}{ Number of scaffold limbs, and orchard no. } & \multicolumn{3}{|c|}{ Per cent of trees with symptoms on: } \\
\hline & 1 scaffold & 2 scaffolds & 3 scaffolds \\
\hline \multicolumn{4}{|l|}{2 scaffold limbs: } \\
\hline Orchard $1 \ldots$. & 20 & 80 & $\ldots$ \\
\hline Orchard $2 \ldots$. & 25 & 75 & . \\
\hline Orchard $3 \ldots \ldots \ldots$ & 17 & 83 & .. \\
\hline Average................... & 21 & 79 & .. \\
\hline \multicolumn{4}{|l|}{3 scaffold limbs: } \\
\hline 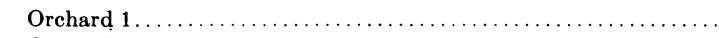 & 4 & 22 & 74 \\
\hline 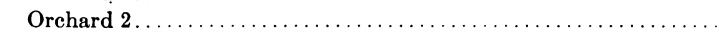 & 0 & 17 & 83 \\
\hline Average... & 2 & 20 & 78 \\
\hline
\end{tabular}

common affected budwood source, some begin to manifest symptoms 1 or 2 years after they are planted, with other trees developing symptoms during the next 5 to 6 years. By this time the trees that developed symptoms at an early age will have produced a succession of bare twigs, with strikingly sparse foliage in consequence. On the other hand, those that developed the disorder only after 5 or 6 years in the orchard may never manifest severe bud failure. The reduction in vegetative growth that accompanies production of a crop by trees at this age apparently tends to check further increases in symptom development (Wilson, 1952).

Variations among trees are equally striking with respect to the level of symptom development on branches of the same tree. With some trees, nonviable buds occur on all branches, and with others nonviable buds occur on only one or two branches. For example, among 56 affected 15-year-old Jordanolo trees in one orchard, 18 produced a subnormal amount of foliage on all branches, and 38 produced subnormal amounts of foliage only on a few branches, with the remaining branches exhibiting little or no evidence of bud failure.

Table 4 gives data on the distribution of symptoms in 10- to 15 -year old affected Jordanolo trees in three orchards. Some trees exhibited symp- 
toms only on branches arising from one scaffold limb, while others exhibited symptoms on branches arising from more than one scaffold limb. This characteristic was utilized for estimating the level of symptom development in the tree. The data show that among trees with two scaffold limbs, 17 to 25 per cent of the trees exhibited symptoms on branches arising from one scaffold limb and 75 to 83 per cent exhibited symptoms on branches arising from both scaffold limbs. Among trees with three scaffold limbs the average per cent exhibiting symptoms on 1, 2, and 3 scaffold limbs was 2, 20, and 78 , respectively.

\section{TESTS FOR PRESENCE OF BUD FAILURE}

In Symptomless Branches of Affected Jordanolo Trees. With all susceptible varieties, certain affected trees may exhibit symptoms only in one or two branches. It was of interest, therefore, to determine whether or not the symptomless branches carried the disorder. As is discussed in the next section, vegetative propagation by budding had confirmed the presence of the disorder in trees that exhibited no discernible symptoms since trees produced from buds of such trees often displayed marked symptoms.

Accordingly, therefore, 50 buds taken from symptomless branches of each of five affected Jordanolo almond trees were placed on young seedling peaches. Three years later, 24 to 33 per cent of the branches produced by buds from each tree displayed unmistakable symptoms of the disorder. As a control for this experiment, buds from Nonpareil trees known to be free of the disorder were placed on the same peach understock. None of these buds produced branches that developed symptoms of bud failure.

In Jordanolo Trees Displaying No Symptoms. Bud failure was demonstrated in three 15-year-old Jordanolo almond trees that exhibited no recognizable symptoms. This was done by placing 25 to 30 buds from each tree on a peach understock. The branches produced by 10 to 17 per cent of the buds from each tree exhibited the disorder 2 to 3 years later. This experiment was concurrent with the experiment described above and the controls were similar.

In Trees Inoculated with Buds from Affected Trees. The discovery of bud failure in Jordanolo trees with no discernible symptoms raised a question regarding the covert existence of the disorder in trees that had been inoculated with affected buds. Since the disorder in the symptomless Jordanolo trees was detected by propagating the Jordanolo buds on another rootstock, it was decided to employ this method with originally nonaffected Nonpareil trees on which affected scions had grown for 9 years. Accordingly, 25 buds from each of three such trees were placed on young almond seedlings. Branches produced by these buds are now 3 years old but none show symptoms of bud failure.

\section{RELATION OF CERTAIN FACTORS TO SYMPTOMS}

Rootstock. Almonds are propagated on three types of rootstocks: seedlings of bitter almond, seedlings of the Texas variety of almond, and seedlings of peach. The bud-failure disorder is found in orchard trees growing on 
all of these rootstocks. In experiments, scions from affected sources develop symptoms as quickly and as severely on one rootstock as on another.

Season. The failure of buds to grow on affected trees is noticeably more pronounced in some seasons than in others. Such variability cannot be attributed solely to the disorder, however. After an exceptionally warm winter, for example, many buds on vegetative shoots may fail to growon both affected and nonaffected trees-because their rest has not been accompanied by sufficient chilling. Through the chilling requirements ${ }^{5}$ of the almond are less than those of other fruit trees, this species nevertheless exhibits a distinct tendency to drop its buds in the spring if the wintertime temperatures have been relatively high.

Alternate-year development of cortical necrosis with more or less regularity is possibly a response to some seasonal condition, though what condition might be involved is difficult to imagine. The alternate-year timing is apparently not a response to conditions within the tree, for it often develops contemporaneously in trees of different varieties and in orchards of the same variety located in different parts of the state. This would require that the internal condition responsible for cortical necrosis be "in phase" in different varieties, a circumstance not likely to occur regularly, at the least.

Soil. The soil apparently plays little or no part in the incidence or in the severity of almond bud failure. Although the disorder occurs quite commonly on one type of soil that is notably low in available potassium, it is as common on other soils that contain sufficient potassium for normal plant growth.

Pruning the Tree. Almond trees are seldom pruned. Excess branches are removed but the bearing wood is not thinned or cut back as in other stonefruits like peaches and apricots. In the hopes of alleviating the effects of the disorder, growers sometimes cut away must of the branch system of affected trees. Such a practice is not beneficial and may at times tend to accentuate the symptoms. For example, mature Peerless almond trees that had shown moderately pronounced symptoms for a number of years, were pruned severely, leaving only the large limbs. Although at first the growth from these limbs was normal, bud failure began to develop in 3 or 4 years. Within 6 years the new top showed symptoms that, if anything, were more pronounced than those shown by the original top.

Where pruning tends to force growth of buds, an effect on the number of buds failing is shown more noticeably the next season. In experiments reported in the next section, growing shoots of affected Peerless and Jordanolo trees were cut back in May. This forced into growth one to five of the lateral buds below the cut. By the end of the season the shoots produced from these buds were 4 to 6 inches long. The next season about half as many buds grew on these shoots as grew on affected nontipped shoots of comparable length.

Vegetative Propagation. The incidence of bud failure among plantings

'According to Chandler $(1951, p .40)$, the buds of most orchard species develop satisfactorily if the average temperature for the 8 or 9 coldest weeks of winter is $42^{\circ} \mathrm{F}$ or lower. Occasionally, however, wintertime temperatures in the Sacramento Valley apparently are not low enough for long enough to meet the chilling requirements of the almond. In such years, apricot trees also lose most of their flower buds from the same cause. 
of the Nonpareil and Peerless varieties is normally low. Consequently, when unusual numbers of affected trees have been found in plantings of these varieties, the disorder in the scion source has been assumed to be rather general. Where it has been possible to trace the budwood to its source this has been found to be so. Surprisingly enough, however, the disorder frequently was less pronounced in the source trees than in the trees produced from them.

In the Jordanolo variety a study was made of the relation between prevalence and severity of the disorder in budwood source trees and prevalence and severity of the disorder in the trees propagated from them. This variety developed from a tree which resulted from a cross between the Nonpareil and Harriott varieties, the former being the female parent. Budwood from the original tree and young trees propagated from it were distributed to interested growers and nurserymen between 1934 and 1937. Nurserymen utilized these trees as their original source of budwood. Reliable information on the budwood history of a number of plantings of this variety has been obtained. In some cases, it has been possible to trace the budwood back through several "scion generations." In doing so it has been helpful to call the foundation tree $S$, trees propagated from it $S_{1}$, trees propagated from $S_{1}$ trees $\mathrm{S}_{2}$, and so on. This notation has been used in the following discussion.

Though nothing is known with respect to the presence of symptoms in the foundation tree, we may safely assume that they were not pronounced or the tree would not have been considered desirable. Of the $S_{1}$ trees, 150 have been examined. Twelve ( 8 per cent) exhibited symptoms of bud failure. Only 2 of the 12 exhibited readily discernible symptoms; the other 10 bore only a few twigs on which noticeable numbers of buds failed to grow. None exhibited cortical necrosis. Among $\mathrm{S}_{2}$ trees, however, the proportion manifesting symptoms was much higher. Moreover, on the whole the $S_{2}$ trees exhibited a more severe form of the disorder than the $S_{1}$ trees, the proportion of twigs with nonviable buds was higher, and cortical necrosis was in evidence. A still further increase of the disorder was noted in $\mathrm{S}_{3}$ trees, particularly with regard to the level of symptom development. Estimates of the level of symptom development were obtained by counting the number of tertiary branches exhibiting symptoms (nonviable buds and profuse twig growth).

The trees under observation had produced from two to five primary or scaffold branches, each primary branch produced two or three secondary branches, and the secondary branches produced a variable number of tertiary branches. These levels of branching were comparatively easy to determine. Since a high degree of correlation existed between the percentage of affected tertiary branches and the percentage of affected small branches, such a method of estimation would give a fair approximation of the symptom level in the tree.

We turn now to specific cases for illustrations of the increase in symptom level that was incident to this vegetative propagation. One such case involved five 17-year-old $\mathrm{S}_{1}$ trees of the Jordanolo variety growing in an orchard near Capay, Yolo County. From these trees the grower propagated several hundred $\mathrm{S}_{2}$ trees, and a local nurseryman obtained budwood from which he 
produced several $S_{2}$ trees, for use in further propagation. About $500 \mathrm{~S}_{3}$ trees, propagated from these $S_{2}$ trees in 1946, were planted in one orchard in Solano County. Thus there were trees of $\mathrm{S}_{1}, \mathrm{~S}_{2}$, and $\mathrm{S}_{3}$ scion generations growing within a relatively short distance from each other.

In 1951 , one of the five $S_{1}$ trees was found with symptoms-a few leafless

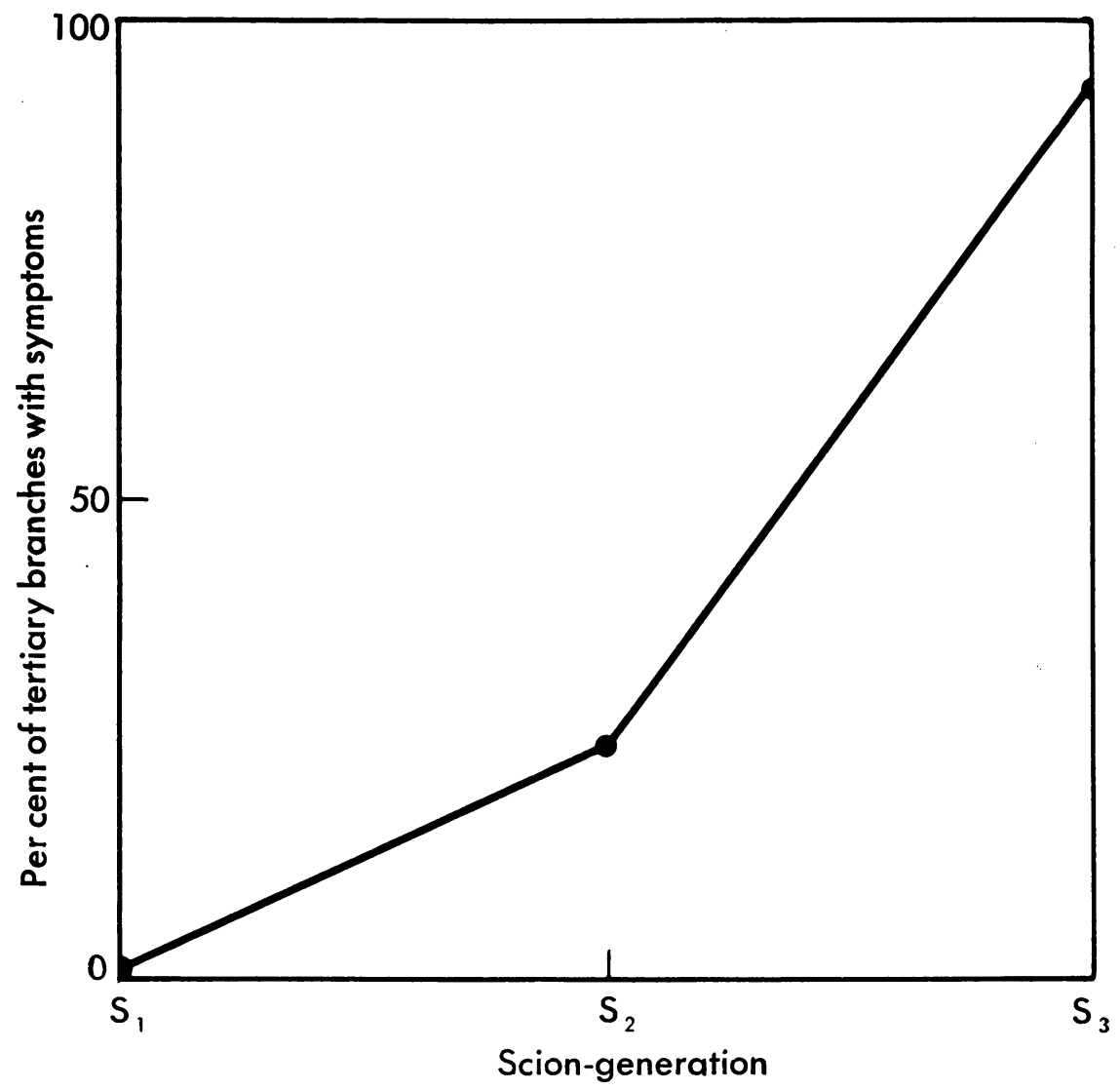

Fig. 9. Per cent of tertiary branches showing bud failure in three scion generations of Jordanolo almond trees.

twigs in the topmost branches-discernible only when the tree was examined carefully. At the same time the disorder was manifested by 33 per cent of the $\mathrm{S}_{2}$ trees 15 years old and by 53 per cent of the $\mathrm{S}_{3}$ trees 5 years old. Even more striking was the difference in severity of symptoms between affected trees of the different scion generations. This is illustrated in figure 9, which shows the average per cent of tertiary branches manifesting symptoms in the affected $\mathrm{S}_{1}, \mathrm{~S}_{2}$, and $\mathrm{S}_{3}$ trees. Whereas only one or two small twigs bore symptoms on one of the five $S_{1}$ trees, a fairly large number of the $S_{2}$ trees exhibited symptoms on most branches. The affected $S_{3}$ trees, though still young, had developed very marked symptoms-an estimated 93 per cent 
of the tertiary branches exhibiting evidence of bud failure and a significant portion having cortical necrosis. As indicated earlier, cortical necrosis appears most frequently in advanced eases of the disorder.

Table 5 contains a further analysis of the exhibition of symptoms by Jordanolo trees that were two and three scion generations removed from the foundation tree. In these particular plantings 47 per cent of the $S_{2}$ trees exhibited symptoms on 1 to 20 per cent of the tertiary branches, while only 14 per cent of the trees exhibited symptoms on 81 to 100 per cent of the branches. For $\mathrm{S}_{3}$ trees, on the other hand, the corresponding percentages were 12 and 62 .

Such data indicate a marked increase in the level of symptom expression

TABLE 5

DIFFERENT DEGREES OF SYMPTOMS EXHIBITED BY JORDANOLO ALMOND TREES OF TWO SCION GENERATIONS

\begin{tabular}{|c|c|c|}
\hline \multirow{2}{*}{ Per cent of tertiary branches with symptoms } & \multicolumn{2}{|c|}{ Per cent of trees in each class } \\
\hline & $\begin{array}{c}S_{2} \text { scion } \\
\text { generation }\end{array}$ & $\begin{array}{c}\mathrm{S}_{3} \text { scion } \\
\text { generation }\end{array}$ \\
\hline 1 to $20 \ldots \ldots \ldots \ldots \ldots \ldots \ldots$ & 47 & 12 \\
\hline 21 to $40 \ldots \ldots \ldots \ldots \ldots \ldots \ldots \ldots \ldots \ldots$ & 12 & 11 \\
\hline$\ldots \ldots \ldots \ldots \ldots \ldots \ldots \ldots$ & 14 & 6 \\
\hline 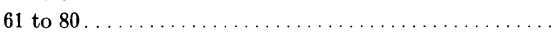 & 13 & 9 \\
\hline 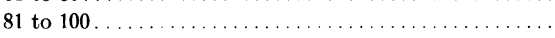 & 14 & 62 \\
\hline
\end{tabular}

between the $S_{2}$ and $S_{3}$ scion generations. Evidence of such an increase was noted in all cases where the $S_{1}, S_{2}, S_{3}$ sequence of scion generations was traced among trees of the Jordanolo variety. The increase was not confined to any particular rootstock; it was found in trees on bitter almond seedlings, Texas seedlings, and peach seedlings.

Evidence of similar behavior of the disorder was seen among trees propagated from other newly developed varieties and crosses. The Jubilee, which suffers from a bud-failure disorder provisionally assumed to be noninfectious by grafting, was developed about 15 years ago from a seedling of unknown parentage. The foundation tree no longer exists, but about 50 trees of the $\mathrm{S}_{1}$ generation were growing near Paso Robles in 1952 with no recognizable symtoms of the disorder. Out of the five $S_{2}$ trees propagated from them by $a$ local nurseryman one manifested the disorder in two branches. Among $S_{3}$ trees propagated from the five $S_{2 .}$ trees, however, severe cases of the disorder were quite common. Trees propagated from some of the seedlings developed in the almond-breeding program at Davis have exhibited bud-failure symptoms similar to those in Nonpareil, Peerless, and Jordanolo. With one such cross the foundation tree exhibits no more than slightly suspicious symptoms, while symptoms are marked in a relatively high proportion of trees of the $\mathrm{S}_{3}$ generation. 


\section{SEASONAL VIABILITY OF AFFECTED BUDS}

While the shoots of trees affected with bud failure are elongating during the growing season, secondary shoots are producéd from growth of buds in the axils of the leaves. Such behavior demonstrates that many of the buds are viable soon after they are produced in summer. To obtain further information on this point it was decided to test the effect of pruning on the buds of affected trees. It is, of course, known that removal of the growing point of a normal shoot frequently forces some lateral buds to grow if they have reached the proper stage of development. Accordingly, in May and June of both 1950 and 1952, 100 growing shoots on each of four affected and four nonaffected Peerless almond trees were pruned, the pruning cut being made at the sixth node below the terminal bud. At that time buds were visible in the axils of the leaves at such nodes. Pruning the shoots in late June forced the growth of very few of the buds at the node on either affected ( 1 to 7 per cent) or nonaffected (3 to 15 per cent) trees. In May, 1950, however, pruning forced into growth 50 per cent of the buds on nonaffected trees and 51 per cent on affected trees. In May, 1952, the corresponding figures were 74 and 85 per cent. No significant differences between affected and nonaffected trees are found in these data.

Evidently it is not until after May of the season in which they are produced that the buds on affected trees lose their viability. As just indicated, 74 per cent of the buds on affected trees were capable of growing in May of 1952. On similar nonpruned affected twigs about 5 per cent of the buds grew in 1952, the year they were produced. The next spring, 69 per cent of the remaining 95 per cent failed to grow. Apparently, therefore, well over half of the buds that were viable in May had lost their viability by the following spring.

Though buds on affected trees may remain viable for some months after they are produced, trials indicate that they possess less vitality than buds on normal trees and that most of them will fail to grow if they are taken from the tree and budded into an understock. In early September, 1950, buds were taken from almond trees with no symptoms of bud failure, from trees with mild symptoms, and from trees with severe symptoms. With few exceptions, when placed on the branches of young peach trees, the almond tissue made organic union with the peach tissue and the bud shield remained green. Presumably, therefore, failure of a bud to grow was seldom due to the failure of a union between scion and understock. In April, 1951, records were compiled on the number of buds growing. These revealed that 81 per cent of buds from nonaffected almond trees remained viable and grew, while only 5 per cent of those from severely affected trees did so. However, a relatively high proportion ( 67 per cent) of the buds from mildly affected trees grew.

\section{SUMMARY}

The disorder of almond trees known as almond bud failure has assumed considerable economic importance in the Sacramento Valley of California. It is known to affect the Nonpareil and Peerless varieties moderately and the Jordanolo variety severely. The Texas and Jubilee varieties are affected 
by disorders provisionally considered to be bud failure, although this has not yet been proved.

The primary symptom is the failure of buds to grow ; secondary symptoms may be excessive shoot production, delay in blossoming, and bark necrosis, their development varying with and depending apparently on the severity of the primary symptom. Bark necrosis, a symptom only in some varieties and occurring most frequently in trees with the severest form of bud failure, tends to develop in alternate years. Except for an almost complete failure of leaf buds to grow at nodes with bark necrosis, the manner in which buds fail follows no consistent pattern. In young trees, failure of the terminal bud is less frequent than failure of the lateral buds; after the trees begin to bear, this pattern is no longer evident.

Tests involving buds and scions from four orchards of Nonpareil and three orchards of Peerless, extending over periods of 11 and 15 years, respectively, have failed to show that the disorders of these varieties were transmissible by grafting or budding. Likewise, tests extending over a period of 3 to 4 years, have failed to show that the disorder of Jordanolo is transmitted by such means. It is concluded that these varieties are affected by a single type of bud failure not transmitted by budding or grafting, hence, noninfectious.

In all tests, however, bud failure developed in the growth from a high percentage of buds and scions from affected trees. The disorder in these three varieties, therefore, is bud-perpetuated. Bud failure was manifested as often in the growth from buds taken from the tree in winter as in the growth from buds taken from the tree in summer.

Bud-failure symptoms develop in scions growing on different rootstocks, such as peach, bitter almond seedlings, and Texas almond seedling.

The proportion of buds lost by affected trees may be much higher in one season than in another. Much of this variability is probably due to causes other than the disorder, because in seasons when affected trees suffer their greatest loss of buds, nonaffected trees also lose considerable numbers. The probable cause of such a phenomenon is the known resistance of buds to breaking dormancy after a particularly mild winter.

Whether the more or less regular development of bark necrosis is affected by climatic or other factors is not determined.

The obvious feature of the disorder is the failure of leaf buds to grow. Many affected twigs devoid of foliage produce flowers that develop fruit. A less obvious feature of the disorder is the effect it exerts on flower-bud differentiation. On normal vegetative shoots, flower buds are usually produced singly at the first four or five subterminal nodes. In the middle nodes of such shoots they are produced as the flanking buds of bud groups. At such positions on affected shoots, however, leaf buds instead of flower buds frequently form. In many cases these subsequently fail.

Wide variations in the manifestation of the primary symptom (failure of buds to grow) occur in trees propagated from a common budwood source. Some trees display the symptom only on one or two branches, others on all.

Trees exhibiting symptoms only in one or two primary branches carry the disorder in the symptomless branches, as was shown by propagating 
buds from such branches on a peach understock. By similar means, certain symptomless trees of bearing age were shown to carry the disorder.

Other evidence that vegetative propagation tends to increase the manifestation of symptoms was found in the study of budwood source histories of the Jordanolo variety. Trees propagated from the foundation (S) tree of this variety, representing the first $\left(S_{1}\right)$ scion generation, developed symptoms less frequently than did trees $\left(\mathrm{S}_{2}\right)$ that were in turn propagated from the first scion generation. Likewise, more $S_{3}$ trees than $S_{2}$ trees developed symptoms. Moreover, the level or severity of symptom increased between $S_{1}$ and $\mathrm{S}_{2}$ trees, and between $\mathrm{S}_{2}$ and $\mathrm{S}_{3}$ trees.

Severe pruning of affected trees apparently tends to increase the severity of symptom expression.

Buds of affected trees were found to be viable soon after they are produced in summer and some of them grew into secondary shoots that season. Lateral buds, many of which would normally fail to grow the next spring, can be forced into growth by removing the terminal bud. Such buds, however, are relatively low in vitality and many of them will fail to grow if removed from the tree in late summer and placed on an understock.

Almond bud failure is transmitted through the seed. Fourteen per cent of one lot of seedlings produced from seeds of affected Nonpareil almond trees exhibited both loss of buds and bark necrosis between 2 and 4 years after the seeds were planted. Certain trees that exhibited no symptoms at 4 years of age were shown, by propagation methods, to be affected.

Brooks, R. H.

\section{LITERATURE CITED}

1940. Comparative histogenesis of vegetative and floral apices of Amygdalus communis with special reference to the carpel. Hilgardia 13: 249-306.

Chandere, W. H.

1951. Deciduous orchards. 436 p. Lea and Febiger, Philadelphia.

Strout, G. L., and E. E. WiLson

1947. Studies of a bud failure condition in almond trees. (Abst.) Phytopathology 37: 364.

Wilson, E. E.

1950. Observations on the bud-failure disorder in Jordanolo, a new variety of almond. (Abst.) Phytopathology 40: 970.

1952. Development of bud failure in the Jordanolo variety of almond. (Abst.) Phytopathology 42: 520 .

1954. Seed-transmission tests of almond bud failure disorders. (Abst.) Phytopathology $44: 510$

Wilson, E. E., and G. L. STouT

1944. A bud failure disorder in almond trees. California Dept. Agr. Bul. 33: 60-64.

1951a. Almond bud failure. In: Virus diseases and other disorders with viruslike symptoms of stone fruits in North America. U. S. Dept. Agr., Agr. Handbook 10: 205-207.

1951b. Drake almond bud failure. In: Virus diseases and other disorders with viruslike symptoms of stone fruits in North America. U. S. Dept. Agr., Agr. Handbook 10: 191-194.

Wilson, E. E., and H. Keith WAgNoN

1955. A peach disorder possibly related to the virus bud failure disease of almond. Phytopathology 45: 323-326.

Wood, Milo N.

1939. Two new varieties of almond: the Jordanolo and the Harpareil. U. S. Dept. Agr. Cir. 542: 1-12. 
The journal Hilgardia is published at irregular intervals, in volumes of about 600 pages. The number of issues per volume varies.

Subscriptions are not sold. The periodical is sent as published only to libraries, or to institutions in foreign countries having publications to offer in exchange.

You may obtain a single copy of any issue free, as long as the supply lasts; please request by volume and issue number from:
Agricultural Publications
Room 22, Giannini Hall
University of California
Berkeley 4, California

The limit to nonresidents of California is 10 separate issues on a single order. A list of the issues still available will be sent on request. 




